\title{
From efficacy to equity: Literature review of decision criteria for resource allocation and healthcare decisionmaking
}

Lalla Aïda Guindo ${ }^{1}$, Monika Wagner ${ }^{1}$, Rob Baltussen ${ }^{2}$, Donna Rindress ${ }^{1}$, Janine van Til ${ }^{3}$, Paul Kind ${ }^{4}$ and Mireille M Goetghebeur ${ }^{1,5^{*}}$

\begin{abstract}
Objectives: Resource allocation is a challenging issue faced by health policy decisionmakers requiring careful consideration of many factors. Objectives of this study were to identify decision criteria and their frequency reported in the literature on healthcare decisionmaking.

Method: An extensive literature search was performed in Medline and EMBASE to identify articles reporting healthcare decision criteria. Studies conducted with decisionmakers (e.g., focus groups, surveys, interviews), conceptual and review articles and articles describing multicriteria tools were included. Criteria were extracted, organized using a classification system derived from the EVIDEM framework and applying multicriteria decision analysis (MCDA) principles, and the frequency of their occurrence was measured.

Results: Out of 3146 records identified, 2790 were excluded. Out of 356 articles assessed for eligibility, 40 studies included. Criteria were identified from studies performed in several regions of the world involving decisionmakers at micro, meso and macro levels of decision and from studies reporting on multicriteria tools. Large variations in terminology used to define criteria were observed and 360 different terms were identified. These were assigned to 58 criteria which were classified in 9 different categories including: health outcomes; types of benefit; disease impact; therapeutic context; economic impact; quality of evidence; implementation complexity; priority, fairness and ethics; and overall context. The most frequently mentioned criteria were: equity/fairness (32 times), efficacy/ effectiveness (29), stakeholder interests and pressures (28), cost-effectiveness (23), strength of evidence (20), safety (19), mission and mandate of health system (19), organizational requirements and capacity (17), patient-reported outcomes (17) and need (16).

Conclusion: This study highlights the importance of considering both normative and feasibility criteria for fair allocation of resources and optimized decisionmaking for coverage and use of healthcare interventions. This analysis provides a foundation to develop a questionnaire for an international survey of decisionmakers on criteria and their relative importance. The ultimate objective is to develop sound multicriteria approaches to enlighten healthcare decisionmaking and priority-setting.
\end{abstract}

Keywords: Decisionmaking, Resource allocation, Priority-setting, Criteria, Healthcare

\footnotetext{
* Correspondence: mireille_goetghebeur@biomedcom.org

'BioMedCom Consultants, Montreal, Quebec, Canada

${ }^{5}$ Department of Health Administration, Faculty of medicine, University of Montreal, Montreal, Canada

Full list of author information is available at the end of the article
} 


\section{Review}

Introduction

Resource allocation and priority setting are challenging issues faced by health policy decisionmakers requiring careful consideration of many factors, including objective (e.g., reason) and subjective (e.g., empathy) elements [1]. Criteria used to evaluate healthcare interventions and allocate resources are likely to have profound implications, especially regarding ethical aspects. Ethical principles of resource allocation set forth by the World Health Organization (WHO) include efficiency (maximizing population health), fairness (minimizing health differences) and utility (greatest good for the greatest number) [2]. Consideration of these often conflicting principles requires pragmatic frameworks and the engagement of a broad range of stakeholders to provide accountability for reasonableness (A4R) [3-7]. Limited resources and inequities in healthcare in both wealthy and developing countries underline the need to allocate optimally [8].

As argued by various authors [9-12], choices may not be based on rational and transparent processes highlighting the need for processes that take this into account. Indeed, if the mechanism employed to guide the distribution of resources is inequitable, the outcome is also likely to be. Thus, how resources are allocated by health policy decisionmakers around the world remains a challenging issue [13]. Priority-setting is defined as the process by which healthcare resources are allocated among competing programs or people [14]. In the context of increasing healthcare costs in many countries around the world, effective approaches to explicit appraisal and priority setting are becoming critical to allocate resources to healthcare interventions that provide the most benefit to patient health as well as contributing to healthcare systems' sustainability, equity and efficiency. Indeed, elucidating decision criteria and how they are considered are key to establishing accountability and reasonableness of decisions and fulfils the A4R framework set forth by Daniels and Sabin [6].

Over the past decades, a number of empirical studies have explored systematic approaches to optimize evaluation of healthcare interventions and priority-setting. A number of tools with defined criteria to evaluate and rank interventions have been developed, recognizing the need for such approaches [10,15-28]. As part of a larger collaborative endeavour exploring decision criteria, the aim of this study was to analyse the peerreviewed literature to identify criteria reported in empirical studies that involved healthcare decisionmakers and in studies describing multicriteria tools. The specific objectives were to identify, categorize and estimate the frequency of decision criteria reported in the literature. This work will support the design of an international survey of decisionmakers on criteria and their relative importance as well as providing a resource for developers of multicriteria-based frameworks.

\section{Methods \\ Search strategy and article selection}

An extensive literature search was carried out in June 2010 on Medline and EMBASE databases to identify articles reporting healthcare decision criteria. Because studies reporting criteria (or factors or principles or components) are usually not indexed with such generic terms and because these terms are used in many fields (e.g., diagnostic criteria), a number of algorithms were explored to optimize the search strategy. The optimized search strategy included the following keywords: "decision-making", "priority-setting", and "resource allocation", combined with "funding", "budget", "cost-benefit analysis", "cost-effectiveness analysis", and "equity". The research was limited to articles published in English, French, or German over the last 10 years and excluded the following types of studies: clinical trials (phase I to IV), editorials, letters, randomized controlled trials, case reports, and comparative studies. Bibliographies of relevant articles were also searched.

Abstracts of articles thus retrieved were screened to identify appropriate inclusion and exclusion criteria. Studies were included if they reported a set (i.e., > 1) of decision criteria and were:

- empirical studies conducted with healthcare decisionmakers (including field-testing of decisionmaking tools, focus groups, questionnaires, interviews)

- reviews of such empirical studies, and

- conceptual studies describing or proposing a set of decision criteria or a decisionmaking tool.

Studies were excluded if they focused on a single criterion (e.g., cost-effectiveness only) or described a priority-setting exercise without explicitly identifying decision criteria. Studies discussing the goals and advantages of priority-setting per se without reporting specific criteria were also excluded. To avoid double-counting of decision criteria, only one publication was included if several publications from the same group described the same set of decision criteria. For the same reason, studies reported in review articles that we included in our analysis and which reported the criteria of the original studies were also excluded.

\section{Data extraction}

Full texts of selected articles were reviewed and data extracted into a table identifying: 1) first author; 2) year of publication 3) method of criteria elicitation or 
identification, 4) decisionmaking setting, 5) exact term for each criterion as reported in the publication.

Given the variability of terms to describe conceptually similar decision criteria, a hierarchical classification system was developed (Figure 1). Terms referring to the same concept (e.g., "side-effects" and "harm") were grouped under one criterion (e.g., Safety). Related criteria were grouped under categories (e.g., Health outcomes and benefits of intervention). This process of classification was guided by the structure of the EVIDEM framework, which includes an adaptable set of core and contextual criteria identified from analyses of the literature, of decisionmaking processes worldwide, and discussions with decisionmakers, and which were structured to fulfill the requirements of multicriteria decision analysis (MCDA; i.e., minimum overlap, mutual independence, operationalizability, completeness and clustering) $[10,18,29]$. MCDA principles were applied in the present study to define criteria regrouping terms referring to the same concept and to categorize criteria into a meaningful and intuitive architecture (clustering).

\section{Descriptive statistics}

The number of times each criterion was cited in the studies retrieved was used as a proxy to identify the criteria perceived to be most important. Descriptive statistics were performed and each occurrence of a term belonging to that criterion was counted. If a study reported two different terms that we grouped under the same criterion, both terms were counted. For example, if a study reported "side effects" and "harm" as separate terms, we counted both of them under the criterion "Safety". The numbers of citations for each criterion and for each category of criteria were analyzed.

\section{Results}

Identification of decision criteria from the literature review The literature search resulted in a total of 2903 records identified through PUBMED and EMBASE database searching and 243 additional records were identified through bibliographic hand searching (Figure 2). These studies were screened by their abstracts and 2790 were excluded. The remaining 364 studies were assessed for eligibility on the basis of full text and 317 articles were excluded. A total of 40 studies were included (Table 1), all of which were published after 1997, and 33 studies from 2006 to 2010. The majority of studies reported criteria derived from interviews and focus groups ( 9 studies each) surveys (2) or literature review of studies (5) conducted with healthcare decisionmakers at micro, meso and macro levels of decision and from several regions of the world. Fourteen studies described multicriteria decisionmaking tools.

\section{Decision criteria classification and descriptive statistics}

Large variations in terminology used to define criteria were observed among the studies included; 360 different terms were identified (Table 2). Using the classification system described above, these terms were assigned to 58 unique criteria which were classified into 9 different categories. These were: A) health outcomes and benefits of intervention (6 criteria), B) types of health benefit ( 2 criteria), C) impact of disease targeted by intervention (4 criteria), D) therapeutic context of intervention (4 criteria), E) economic impact of intervention (9 criteria), F) quality/uncertainty of evidence (6 criteria), G) implementation complexity of intervention (9 criteria), H) priorities, fairness and ethics (7 criteria), I) overall context (11 criteria). Categories were defined to: i) regroup criteria pertaining to the same overall concept (e.g., category "A - Health outcomes and benefits" of intervention includes criteria such as health benefits, life saving, efficacy, effectiveness, safety, patient-reported outcomes and quality of care) and to ii) disentangle criteria specific to the intervention (categories A to F) from criteria specific to the context ( $\mathrm{G}$ to $\mathrm{I}$ ).

The classification system and the number of citations for each criterion are reported in Figure 3. The ten most

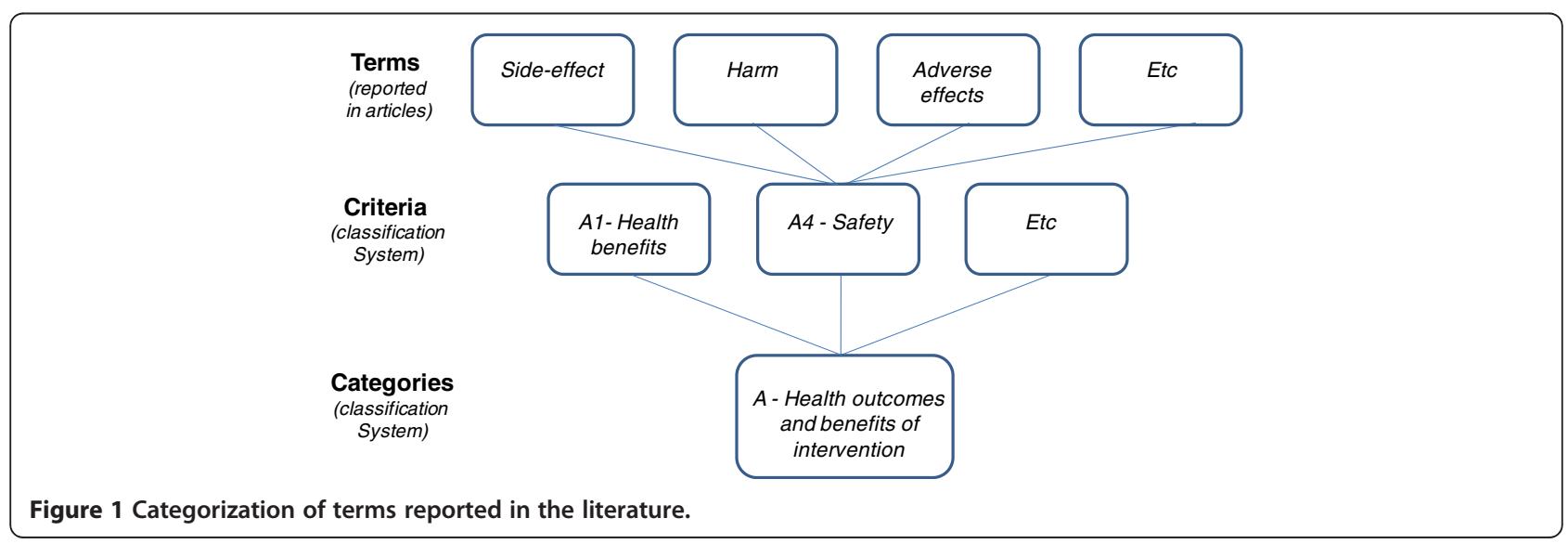




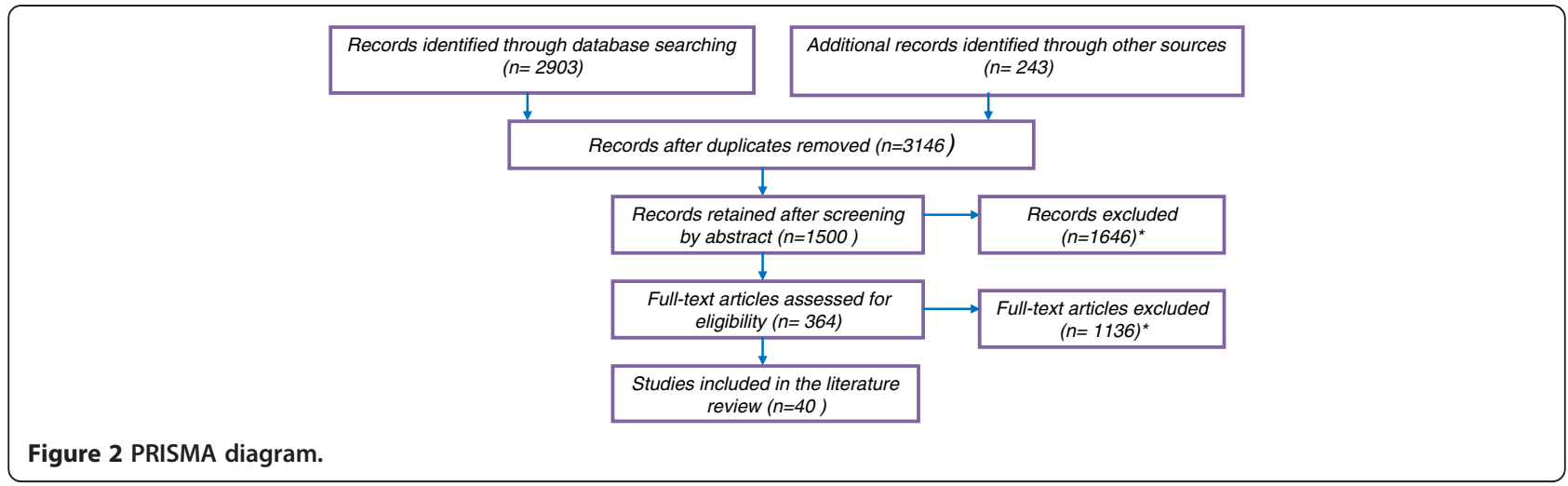

frequently mentioned criteria were: equity, fairness and justice (H4, 32 citations); efficacy/effectiveness (A2, 29 citations); stakeholder interests and pressures (I11, 28 citations); cost-effectiveness (E5, 23 citations); strength of evidence (F2, 20 citations); safety (A4, 19 citations); mission and mandate of health system (I1:19 citations); organizational requirements and capacity (G2, 17 citations); patient-reported outcomes (A5, 17 citations); and

Table 1 Studies identified in the literature and included in the analysis

\begin{tabular}{|c|c|c|}
\hline \multicolumn{2}{|c|}{ Studies reporting on decision criteria } & \multirow[t]{2}{*}{ Studies describing a decisionmaking tool } \\
\hline Authors & Type of study and level of decisionmaking* & \\
\hline 1. Andreae et al. [9], 2009 & Survey, macro & 1. Bowen et al. [15], 2005 \\
\hline 2. Asante et al. [8], 2009 & Interviews, meso \& macro & 2. Browman et al. [16], 2008 \\
\hline 3. Baltussen et al. [12], 2007 & Focus group, macro & 3. Ghaffar et al. [17], 2010 \\
\hline 4. Baltussen et al. [30], 2006 & Focus group, meso \& macro & 4. Goetghebeur et al. $[10,18], 2008,2010$ \\
\hline 5. Baltussen et al. [11], 2006 & Methodology & 5. Golan et al. [19], 2010 \\
\hline 6. Dionne et al. [31], 2009 & Interviews, macro & 6. Hailey et al. [20], 2009 \\
\hline 7. Dolan et al. [32], 2010 & Methodology & 7. Honore et al. [21], 2010 \\
\hline 8. Duthie et al. [33], 1997 & Interviews, micro, meso \& macro & 8. Johnson et al. [22], 2009 \\
\hline 9. Gibson et al. [34], 2006 & Focus group \& interviews, meso \& macro & 9. Kirby et al. [23], 2008 \\
\hline 10. Hofmann et al. [35], 2005 & Literature review & 10. Meagher et al. [24], 2010 \\
\hline 11. Irving et al. [36], 2010 & Interviews, micro & 11. Menon et al. [25], 2010 \\
\hline 12. Jehu-Appiah et al. [37], 2008 & Focus group, macro & 12. Tannahill et al. [26], 2008 \\
\hline 13. Kapiriri et al. [38], 2009 & Interviews, micro, meso \& macro & 13. The University of York [27], 2002 \\
\hline 14. Koopmanschap et al. [39], 2010 & Focus group, macro & 14. Wilson et al. [28], 2006 \\
\hline 15. Lasry et al. [14], 2010 & Interviews, macro & \\
\hline 16. Lehoux et al. [40], 2007 & Literature review & \\
\hline 17. Lopert et al. [41], 2009 & Focus group, macro & \\
\hline 18. Martin et al. [42], 2001 & Focus group, macro & \\
\hline 19. Mitton et al. [43], 2006 & Focus group, macro & \\
\hline 20. Mullen et al. [44], 2004 & Survey, meso & \\
\hline 21. Noorani et al. [45], 2007 & Literature review and interviews, macro & \\
\hline 22. Saarni et al. [46], 2008 & Consensus procedure, macro & \\
\hline 23. Vuorenkoski et al. [47], 2008 & Literature review & \\
\hline 24. Wilson et al. [48], 2007 & Focus group, macro & \\
\hline 25. Wirtz et al. [49], 2005 & Interviews, macro & \\
\hline 26. Youngkong et al. [13], 2009 & Literature review & \\
\hline
\end{tabular}


Table 2 Classification of terms reported in the literature

\begin{tabular}{ll}
\hline $\begin{array}{l}\text { Categories of classification } \\
\text { system }\end{array}$ & \multicolumn{1}{c}{$\begin{array}{c}\text { Criteria of classifica } \\
\text { system }\end{array}$} \\
\hline $\begin{array}{l}\text { A-Health outcomes and } \\
\text { benefits of intervention }\end{array}$ & Number of criteria: 6 \\
& $\begin{array}{c}\text { A1: Health benefits: } \\
7 \text { terms, cited } 10 \text { times }\end{array}$ \\
& A2: Efficacy/effectiveness: \\
& 11 terms, cited 29 times
\end{tabular}

A3: Life saving:

4 terms, cited 5 times

A4: Safety: 11 terms, 19 times

A5: PRO: 10 terms,

17 times

A6: Quality of care: 1 term, 1 time

\section{B-Type of health benefit}

\section{C-Impact of the disease targeted by} intervention

\section{D-Therapeutic context of intervention}

Number of criteria: 4

D1: Treatment alternatives: 5 terms, 13 times

D2: Need: 8 terms, 16 times

D3: Clinical guidelines \& practices: 4 terms, 7 times

\section{Terms used in articles}

Number of terms: 44

- A1 - health benefits[13,31,38,50], potential health gain[44], enhanced health outcomes[44], relative advantage[51], health effects[30], additional effects[22], incremental health gain[43]

- A2 - efficacy[13,47], efficacy/effectiveness[10,19,20,25,27,28,44,48], effectiveness[14,22,26,32-34,48], clinical benefit[19,22,24,42,47], clinical impact[45], clinical merit[22], relative clinical benefit in relation with current standards[16], determine relative value for degree of benefit against benchmarks[16], magnitude of treatment effect[22] response rate[43], onset and duration of treatment/program effect[43]

- A3 - prolongation of disease-free survival[42], saving life[19], life expectancy gains[13], average life-year benefit per patient[13,33]

- A4 - side effects[33,41,47], unintended consequences[40], safety[9,22,26,31], safety and tolerability[10,19,20], risks[20,22], risk management[44], harm[42], adverse effects[32], inconvenience[22], risk of event[22], reduction in symptomatic toxicity compared with standard therapy[42]

- A5 - patients reported outcomes[10], quality of life[19,42,44,52], impact on quality of life[22,43], number of QALYs gained per patient[36,39], disability adjusted life years[13], likely impact on patient[16], patient preference[25], patient autonomy[26,35,40], relative value to patient[16], best for patient[38]

- A6 - overall gain in quality of care[44]

Number of terms: 12

- B1 - public health interest[10], population effects[19], prevention[19,28], prevention of ill health[44], social impact[13,22,33], social benefit[13,22,33]

- B2 - type of medical service[10], relief/prevention of symptoms/complications of disease[42], health gain or maintenance[44], individual effects[19], individual impact and benefit[13,33], the composition of the health gain[39]

Number of terms: 21

- $\quad$ C1 - severity of disease $[9,10,13,19,30,37,39,47]$, impact of the disease/condition on quality of life[43]

- $\quad$ C2 - determinants (the factors responsible for the persistence of the burden)[17], characteristics of target condition[22]

- C3 - burden of disease[9,13,22,33], disease burden[17,25,45,48], burden of illness[22], burden of therapy[22], cost to treat disease[33], cost to prevent disease[33], national cost of the disease/condition to the healthcare system[43]

- C4 - prevalence[9,13], number of potential beneficiaries[35,37,40], indirect beneficiaries[40], size of population[10,19], prevalence and incidence of disease[23,25,43], number of residents benefiting[44], number of clients served[43], number of patients[47], social/demographics[22], incidence[22]

Number of terms: 18

- D1 - treatment alternatives[13,22], availability of alternatives[16,19,25,42,44,47], availability of effective intervention and preventable[13], alternatives[35,40,45], benchmark comparators[16]

- D2 - comparative interventions limitations (unmet needs)[10], need[19,22,28,38,42,44,49], clinical impact (need and trends)[24], emergencies and need[13], apparent need[14], clinical need[36,41,50], desirability of effects[40], meets patient's basic need[38]

- D3 - evidence-based guidelines[13,33,36], best practice[14], clinical guidelines[10,23], academic health center research (establishing/or using best practice)[24] 
Table 2 Classification of terms reported in the literature (Continued)

\begin{tabular}{|c|c|c|}
\hline & $\begin{array}{l}\text { D4: Pre-existing use: } \\
1 \text { term, } 1 \text { time }\end{array}$ & \\
\hline \multirow{3}{*}{$\begin{array}{l}\text { E-Economic impact } \\
\text { of intervention }\end{array}$} & Number of criteria: 9 & Number of terms: 36 \\
\hline & $\begin{array}{l}\text { E1: Cost: } 3 \text { terms, } \\
11 \text { times }\end{array}$ & $\begin{array}{l}\text { - E1 - cost per patient[19], costs[19,20,22,27,32,42,44,47,51] } \\
\text { unit cost[22] }\end{array}$ \\
\hline & $\begin{array}{l}\text { E2: Budget impact: } \\
6 \text { terms, } 11 \text { times }\end{array}$ & $\begin{array}{l}\text { - E2 - budget impact on health plan[10,19,25,47], total } \\
\text { budget impact[30], budget impact[32,45,47], usage and cost } \\
\text { implications of competing new drugs if approved[16], } \\
\text { affordability[25], operating and start-up costs[43] }\end{array}$ \\
\hline
\end{tabular}

E3: Broad financial impact: 7 terms, 7 times

\section{E4: Poverty reduction: 1 terms, 3 times \\ E5: Cost-effectiveness: 5 terms, 23 times}

E6: Value: 2 terms, 3 times

E7: Efficiency and opportunity costs: 6 terms, 10 times

E8: Resources: 5 terms, 6 times

E9: Insurance premiums: 1 term, 1 time

F-Quality and uncertainty of evidence

G-Implementation complexity of intervention
Number of criteria: 6

F1: Evidence available: 7 terms, 9 times

F2: Strength of evidence: 14 terms, 20 times

F3: Relevance of evidence: 5 terms, 8 times

F4: Evidence characteristics: 5 terms, 7 times

F5: Research ethics:

2 terms, 4 times

F6: Evidence requirements: 1 term, 1 time

Number of criteria: 9

G1: Legislation: 6 terms, 6 times

G2: Organizational requirements and capacity to implement: 15 terms, 17 times
- E3 - impact on other spending[10], financial impact on government[13], economic impact[45], economics[22], national medical costs per-year[39], cost-saving[33], national saving in costs of absence per year[39]

- E4 - positive poverty reduction[13,30,37]

- E5 - cost-effectiveness[9,10,13,14,17,20,22,25-27,30,34,37,39,41,44], economic evaluations[27], cost and consequences[9,13,14,41], pharmacoeconomic analysis[23], cost utility expressed as cost per QALY[22]

- E6 - value for money[32,44], financial value[44]

- E7 - efficiency of intervention[31], efficiency[10,19,22,23,44], opportunity costs[10], opportunity costs to the population/society[16], best within available resources[38], interdependencies[50]

- E8 - resources[17,51], variation in rate of use[45], available resources[13], resources implications[50], volume of activity[13]

- E9 - impact on health insurance premiums[9]

Number of terms: 34

- F1 - evidence[22,42,45], proof[22], scientific evidence[47], current level of knowledge[17], time of assessment in technology development[35], timelines of review[45], therapy mechanism of action[23]

- F2 - strength of evidence[16,44], quality of evidence[47], quality of data and past decisions[47], quality of data[22], quality[26], validity of evidence[10,19], related degree of knowledge certainty[23], certainty[48], consistency[19,22,44], consistent[38], completeness and consistency of reporting evidence[10], openness[26,44], selection of studies[35,40], precision of treatment effect[22]

- F3 - relevance of evidence[10,19], representativeness of users (studies vs. real world)[35,40], level of generalization[35,40], effectiveness in real practice[22], evidence of effectiveness[44]

- F4 - normative characteristics of study[35,40], choice of endpoints[35,40], clinical trial data[47], multiple randomized trials or meta-analysis/single randomized trial of reasonable size/small randomized trial[42], phase II[53]

- $\quad$ F5 - research ethics[35,40], informed consent[26,40]

- F6 - adherence to requirement of decision making body[10]

Number of terms: 57

- G1 - legal arrangements[40], legislative issues[22], medical liability[40], human rights legislation[23], legal implications[45], conformity of programs[22]

- G2 - system requirements[25], physical environment [44], environment[22,26], system capacity[10], local capacity[17], ability to implement[38], implementation[22], organization's structure[51], organizational burden[49], logistics[36], process[28],

well-organized[38], organizational feasibility[22,25], feasibility of delivery[16], deliverability[48] 
Table 2 Classification of terms reported in the literature (Continued)

G3: Skills: 6 terms, 6 times

G4: Flexibility of
implementation:
7 terms, 8 times

G5: Characteristics of intervention: 6 terms, 8 times

G6: Appropriate use: 3 terms, 3 times

G7: Barriers and acceptability: 3 terms, 4 times

G8: Integration and system efficiencies: 9 terms, 9 times

G9: Sustainability: 2 terms, 4 times

\section{H-Priorities, \\ fairness and ethics}

Number of criteria: 7

H1 Population priorities:

5 terms, 5 times

H2 : Access: 10 terms, 17 times

H3 : Vulnerable and needy population: 9 terms, 11 times

H4: Equity, fairness and justice: 12 terms, 32 times

H5 : Utility: 2 terms, 3 times

H6: Solidarity: 6 terms, 8 times

H7: Ethics and moral aspects: 11 terms, 14 times

Number of criteria: 11

11: Mission and mandate of health system: 13 terms, 19 times

12: Overall priorities: 6 terms, 6 times
- $\mathrm{G} 3$ - knowledge and skills[51], nature of staff[51], clinical education and training[44], human resources availability[17], recruitment and retention of staff[44], attracting/retaining scarce clinical staff[44]

- G4 - flexibility[51], reversibility[51], trialiability[51], revisability[51], ability to evaluate[22], provision for revision/appeals[38], engagement[26,48]

- G5 - characteristics of intervention[22], complexity of the intervention[51], components of technology[35], autonomy of the intervention[38], autonomy[17,26,46], convenience[42]

- G6 - appropriate use of intervention[10], appropriateness[44], appropriate setting/level of service[43]

- G7 - acceptability[22,48], responsiveness[44], controversial nature of proposed technology[45]

- G8 - system integration (best use of elements of healthcare system)[34], integration into local community[44], ease of integration[22], impact on other services[40], links to other services[44], compatibility[22], reduction of the monitoring[33], reduction of waiting list size[33], impact[22]

- G9 - sustainability[23,24,26], longevity[19]

Number of terms: 55

- $\quad \mathrm{H} 1$ - perspective and current priority[13], target and priority-setting[14], known priorities[44], population priority[10], coverage of selected conditions[13]

- H2 - population access[10], access[19,27,47,49], equity of access improvement[13], access to care easier[31,33,34], distribution and access to healthcare[35,40], accessibility[22,44], equity of access[44], access to health system[22], geographical equity[43], timeliness of access[43]

- H3 - vulnerable population[37,38], potential victims[40], particular social groups with high risk and/or increased vulnerability[23], compassion for the vulnerable[19], particularly needy/vulnerable groups[44], age of targeted group[13,30], maternal mortality[13], quality of maternity care services[13], population equity[43]

- H4 - equity[8,13,14,19,22,25,27,40,44,46,48], fairness[10,14,40,44,47], health equity[23,26], equality[19,26,38], distributive justice[23,25], formal justice[23], social justice[23], justice[26,46], social injustice[40], addressing health status inequalities at a population level[44], human integrity and dignity[35,40], basic human rights[35]

- H5 - utility[10,26], utilitarism[25]

- H6 - solidarity[19,25,26], collectivism[26], mutuality[26], reciprocal trust[40], diversity[26], cohesion[26]

- H7 - ethics[14,22], ethical values[22], values[22], values and beliefs[51], consistency with societal values[22], ethical implications[45], moral obligation to implement a technology[35,40], rule of rescue[25], priority to basic and necessary care[38], moral consequence of HTA $[35,40]$, moral challenges related to certain components of HTA[35]

Number of terms: 83

- $\quad 11$ - goals of healthcare[52,53], goals[21], beneficence[28], nonmaleficience and justice[28], beneficence/non-maleficience[17,26,53], strategic fit[9,23], medical and social worth[45], relevance[22], present social consensus, $[17,49]$ consensus regarding public funding of a therapy[17,53], government mandate[17], national standards[24], healthcare context positioning[23]

- 12 - national priorities[45], national or board priority[14], local and national priorities[8], international priorities[45], alignment with external directives[9], strategic direction[43] 


\section{Table 2 Classification of terms reported in the literature (Continued)}

\author{
13: Financial constraints: \\ 8 terms, 13 times \\ 14: Incentives: \\ 4 terms, 5 times \\ 15: Political aspects: \\ 5 terms, 7 times \\ 16: Historical aspects: \\ 3 terms, 3 times \\ 17: Cultural aspects: \\ 7 terms, 10 times
}

18: Innovation:

3 terms, 3 times

19: Partnership and

leadership: 8 terms,

9 times

\author{
110: Citizen involvement: \\ 3 terms, 3 times \\ 111: Stakeholders \\ interests and pressures: \\ 23 terms, 28 times
}

- 13 - budget constraints[13,33,45], cost-containment[42,49], budget level[13,19,45], social economical context[16], limited provincial health resources[17], budget implementation challenges[17], economic feasibility[37], reliance of other services/sectors(on investment)[14]

- 14 - financial incentives[28,45], organizational support[16], donor involvement[31], incentives for compliance[20]

- $\quad 15$ - political pressure[13,19,45], political components[52], politically and legally defensible decisions[42], politics[37], political impact[37]

- 16 - historical components[52], past experiences[16], historical budgets[19]

- $\quad 17$ - culture and religious convictions[19,28,47], stigma[28], compatibility with values[16], challenge of social and values arrangements[28,47], conception of certain persons or disease[47], psychosocial implications[34], public preference[14]

- 18 - perceived benefits of change[16], innovativeness[37], generation or application of knowledge[43]

- 19 - partnership and networking[16], partnerships[9], maintaining relationship[42], leadership[16], community development[53], academic commitments: research and education[9,23], partnership and collaboration across organizations[43], contribution to position as a learning organization[43]

- $\quad 110$ - citizenship[53], ownership[53], enabling health literacy (empowerment)[53]

- 111-stakeholders pressure[52], advocacy[16,45], pressure from physician and patients groups and past decisions[32], clinical expert opinions[37], patient representative group opinions[37], power relations among stakeholders[28], user of the technology interests[47], challenge the relationship between patient and physician[47], professional prestige[28,47], clinicians excitement and decisions in other hospitals[32], public reaction and public accountability[28], HTA's producer interest[28,47], company activities[32], researchers ethics interests[28,47], third party agents involved[47], recommendations made by other countries[13], status in other jurisdictions[49], current status of public funding in other jurisdictions[17], drugs used in other hospitals[32], expressed demand[14,37], patient demand[32], expected level of interest (patient and medical)[34], entitlement[28]

This table is reporting all the terms (338) extracted from the selected articles and tabulates them using the classification system developed for this study, which is based on a hierarchical approach clustering 58 criteria into 9 categories.

need (D2, 16 citations). Among these 10 most frequently cited criteria, three criteria were from the category "A - Health benefits and outcomes of intervention", highlighting the importance of this consideration in decisionmaking. The other most frequently cited criteria were from seven categories of criteria, indicating that the classification system captured critical criteria in distinct categories.

At the category level (Figure 4), the number of citations was the highest for the category of criteria "Overall context" (106 citations); followed by "Priorities, fairness and ethics" (90 citations); "Health outcomes and benefits of intervention" (81 citations); "Economic impact of intervention" (75 citations); "Implementation complexity of intervention" (65 citations); "Quality and uncertainty of evidence" (49 citations); "Impact of disease targeted" (40 citations); "Therapeutic context of intervention" (37 citations); and "Type of service provided" (18 citations).

\section{Discussion}

This literature review revealed a burgeoning number of studies examining healthcare decision criteria and criteria-based decisionmaking tools, especially over the last five years. Criteria were identified from studies performed in several regions of the world involving decisionmakers at micro, meso and macro levels of decision and from studies reporting on multicriteria tools. Increasingly, the healthcare community is aware that beyond cost-effectiveness, other criteria must be taken explicitly into account for transparent and consistent healthcare decisionmaking and priority-setting [54-56]. Indeed, elucidating decision criteria and how they are considered are key to establishing accountability and reasonableness of decisions. This is necessary to fulfill the relevance condition of the accountability for reasonableness (A4R) framework of Daniels and Sabin [6], which states that "Decisions should be made on the basis of reasons (i.e. evidence, principles, values, arguments) 


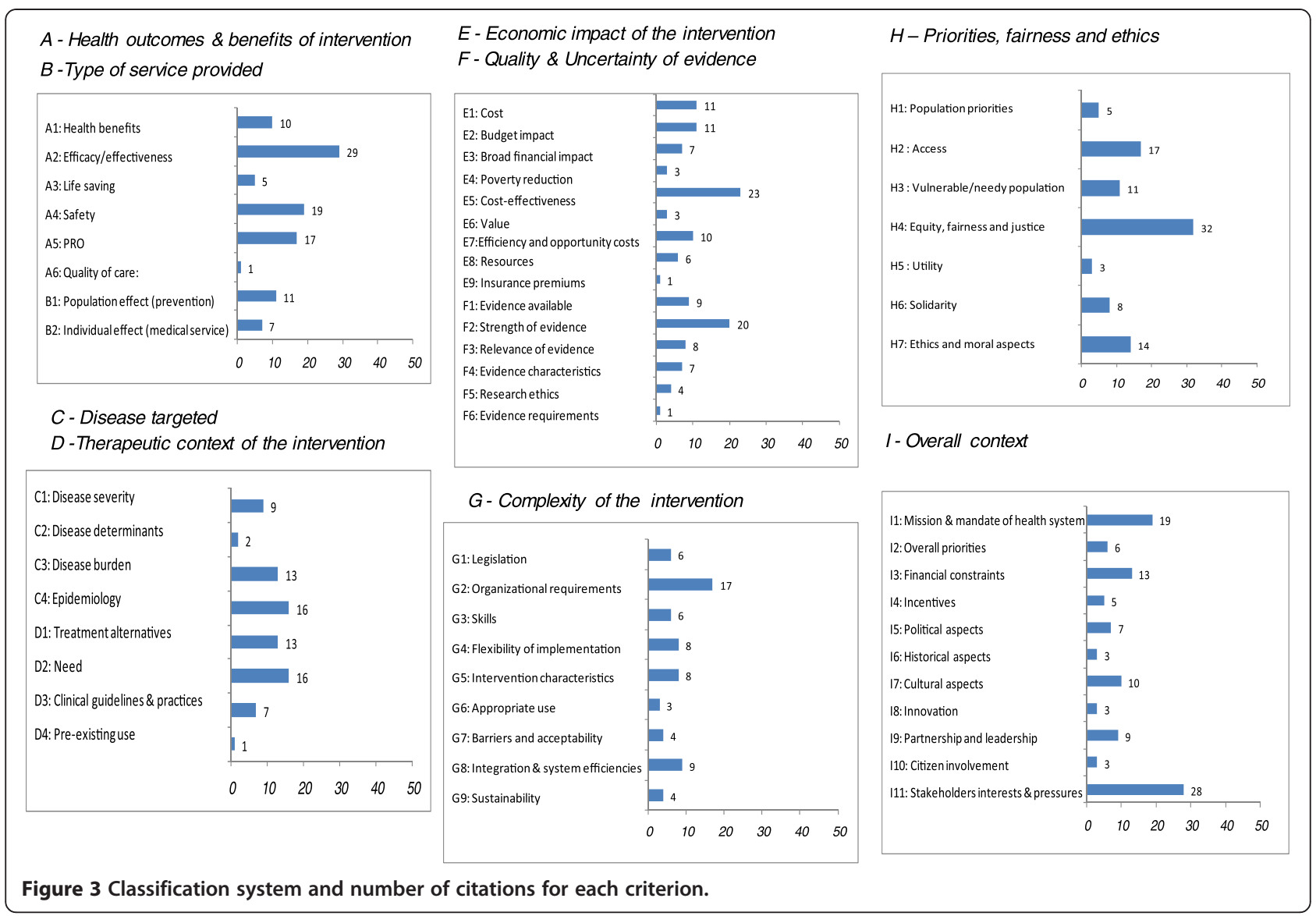

that 'fair-minded' stakeholders can agree are relevant under the circumstances".

This analysis revealed a predominance of normative criteria, that is, answering the question "what should be done?" This highlights the importance of considering the actual worth or value of healthcare interventions rather than just feasibility criteria, ("What can be done?"). Of the ten most frequently cited criteria, eight were normative (equity and fairness, efficacy, cost-effectiveness, strength of evidence, safety, mission and mandate of healthcare system, need, patient-reported outcomes) and two were feasibility criteria (stakeholder pressures and interests, organizational requirements and capacity). This is aligned with a review of studies on decision
A - Health outcomes and benefits of intervention
B-Type of service provided
C - Impact of disease targeted
D - Therapeutic context of intervention
E- Economic impact of intervention
F - Quality and uncertainty of evidence
G - Implementation complexity of intervention
$H$ - Priorities ,fairness and ethics
I- Overall context

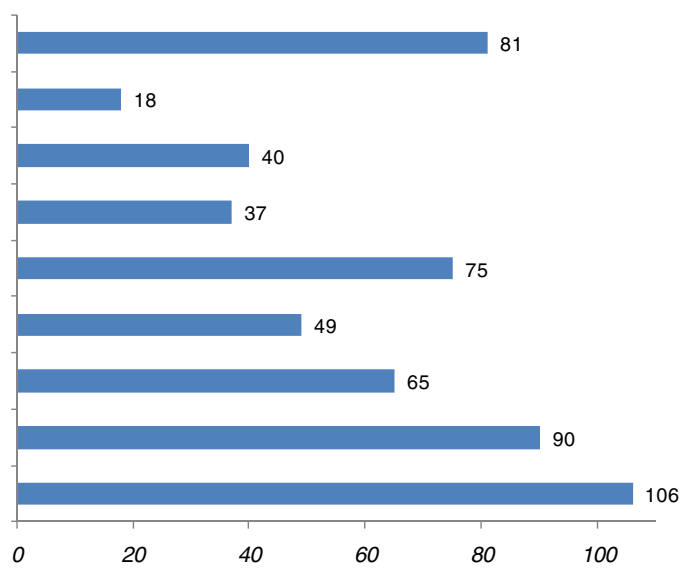

Figure 4 Number of citations for each category of criteria of the classification system. 
criteria in developing countries [13], and points to the need to include both normative and feasibility criteria in decision and prioritization tools to fully reflect and support the decisionmaking process.

The criterion "equity and fairness" was the most frequently reported. This may reflect that equity is a guiding principle in defining the values on which decisions are based. Equity is difficult to operationalize in decisionmaking and priority-setting processes in a pragmatic manner. It is a complex ethical concept that eludes precise definition and is synonymous with social justice and fairness [57]. It is referred to as "a fair chance for all,"[23] "equality of access to healthcare resources on the basis of need," [8] "absence of systematic disparities in health (or in the major social determinants of health) between groups with different levels of underlying social advantage/disadvantage"[58]. The WHO advocates concepts of "horizontal equity, providing healthcare to all those who have the same health need, and vertical equity, providing preferentially to those with the greatest need" [57]. The difficulty of considering equity in a pragmatic manner points to the need to include it systematically as operationalizable criteria in the decision process. If not systematic, it is less likely that decisions will be equitable. Decisions are generally fairest when standards are predetermined, explicit and consistently applied [59]. Equity is embedded in consideration of disease severity in prioritization of healthcare interventions. Decisionmakers generally attach more value to interventions for severe disease than for mild disease. This is also translated in the worst-off principle, which relates to an independent concern for severity; "the worse off an individual would be without an intervention, the more highly society tends to value that intervention" [60]. Systematic consideration of criteria defined on the basis of population priorities identified by decisionmakers (e.g., more value for interventions targeted to vulnerable populations such as children, the elderly, those in remote areas) is another pragmatic way to incorporate equity into decisionmaking. Integration of ethical considerations in operationalizable criteria was developed for the comprehensive multicriteria framework EVIDEM [61]. Ethical issues are an integral part of the EUnetHTA core model to ensure their explicit considerations [46], and several frameworks focusing on equity [62] and ethical issues [63] have recently emerged.

Efficacy/effectiveness was the second most frequently reported criterion; as Hawkes discussed recently, "governments are wrestling with the issues of efficacy and fairness in healthcare delivery" [64]. While efficacy measures the effect of an intervention treatment under controlled conditions (such as during clinical trials), effectiveness provides critical information on outcomes actually achieved by an intervention in real life settings. Efficacy and effectiveness are fundamental criteria considered at the regulatory (e.g., FDA, EMA) and reimbursement levels for medicines in many jurisdictions [65-67]. Because decisions concerning interventions at policy, clinical and patient level are made with reference to a given context of care (usually standard of care), improvement over existing care rather than absolute efficacy or effectiveness provides the most informative evidence [10]. Indeed, decisions about usefulness of interventions are usually based on relative advantage compared to existing approaches [15]. Comparative effectiveness, "the comparative assessment of interventions in routine practice settings" [68] is meant to help answer the question "does it work in my context?" and is demand-driven research aimed directly at decisionmaker needs [69]. For new interventions, however, effectiveness data is usually not available and decisions are often made on the basis of efficacy data, with the uncertainty inherent in innovation [67]. Evidence-based decisionmaking relies on actual benefits derived from an intervention so mechanisms (such as defining subcriteria) outlining specifically the most relevant outcomes of efficacy/effectiveness in real life are critical to ensure that the dimensions of efficacy/effectiveness are fully captured and communicated.

The third most commonly reported criterion refers to stakeholder interests and pressures. Macro-level decisions are influenced by public pressure and advocacy $[13,15,38]$ and the demand for a new program is a powerful argument for decisionmakers at the political level [70]. In a study exploring the basis for immunization recommendations, while vaccine safety was reported as important or very important in making immunization recommendations by all countries regardless of economic status, low and lower middle income countries were significantly more likely than developed countries to report that public pressure was an important factor [9]. Because pressures from groups of stakeholders are often part of the context [10], being aware of pressures and interests at stake and how they may affect decisionmaking and implementation is important and should be explicitly tackled using a framework that encourage systematic consideration of their potential implications when making healthcare decisions.

Cost-effectiveness was the fourth most commonly reported criterion. Cost-effectiveness is frequently used in healthcare decisionmaking $[65,71]$ but its usefulness is the subject of debate $[54,56]$. A review of 36 empirical studies reported that the influence of cost-effectiveness was moderate at micro, meso and macro levels of decision [55]. Designed to incorporate several criteria of decision (e.g., cost, efficacy/effectiveness, safety, quality of life) into an aggregated ratio allowing comparisons of interventions, it fails to include important criteria such as equity and the severity of the targeted condition [59]. 
In addition, cost-effectiveness thresholds are commonly mistaken for affordability thresholds [59]. Beyond costeffectiveness ratios, health economic studies generate data that are necessary to evaluate healthcare interventions (e.g., resource utilization and cost consequences of a new intervention compared to existing care).

This study also revealed that strength of evidence is an important aspect in decisionmaking, highlighting the influence of evidence-based medicine. Evidence is usually sought to demonstrate effectiveness ("it works"), show the need for policy action ("it solves a problem"), guide effective implementation ("it can be done"), and clarify cost-effectiveness ("it provides value for money") [15]. The quality of evidence that decisionmakers use can only be determined when several concepts are considered, such as scientific validity, completeness and relevance to the decisionmaking context [18]. The strength of evidence builds with time as interventions are used in real life and initial decisions made in a context of uncertainty (e.g., randomized clinical trial data in limited populations) may be revisited as evidence accumulates. A common question is how much evidence is enough to make an evidence-based decision [59]. Beyond scientific evidence, decisionmaking also relies on colloquial evidence [72]. Consideration of strength and quality of the different types of evidence remain an important part of the appraisal of interventions.

Safety, a critical element of policy and clinical practice, was the sixth most cited criterion. Safety refers to the frequency and severity of adverse events or complications arising as a result of using the new technology compared to an alternative [22]. Efficacy and safety are the main criteria in the initial evaluation of a new intervention [70]. And the risk-to-benefit equation is a critical component of clinical and regulatory decisionmaking [67].

A number of other criteria were identified highlighting the complexity of healthcare decisionmaking and the need to support this process with tools to ensure consistency, transparency and accountability for reasonableness. An important milestone towards that goal would be to harmonize terminology. Indeed, a large variety of terminology was found in the literature during analysis and classification of criteria. Although a systematic approach was used to classify terms into criteria and overarching categories using the principles of MCDA, such analyses are limited by the subjective interpretation of terms reported by authors. For example, the terms reported in published studies such as "side effects," "unintended consequences," "risks," "harm," or "adverse effects" were all grouped under the criterion "Safety." These variations of terminology underline the difficulty of harmonizing the decisionmaking processes, as several authors have noted [10,11]. It calls for well-defined criteria to avoid confusion and ensure sound application of multicriteria approaches to decisionmaking $[11,73]$.

Although this analysis was limited to published studies, an extensive analysis of decisionmaking processes from jurisdictions around the world for coverage of healthcare interventions was performed to define the criteria of the EVIDEM framework, which are included in this analysis $[10,18]$. In addition, the large number of terms retrieved covers criteria currently used in more than 25 decisionmaking processes for coverage of medicines [65].

\section{Conclusion}

This study highlights the importance of considering both normative and feasibility criteria for decisionmaking and priority setting of healthcare interventions. By providing a comprehensive classification of decisionmaking criteria, this analysis can promote reflection on the value of harmonizing terminology in this field. It can also serve as a resource when considering which criteria to include in sound multicriteria approaches (i.e., fulfilling principles of completeness, lack of redundancy, mutual independence, operationalizability and clustering). This analysis is also used as a foundation for the development of an international survey on criteria expected to further expand our knowledge of real-life decisionmaking and advance multicriteria approaches.

Such approaches have the potential to integrate and facilitate pragmatic operationalization of a large range of considerations, including ethical considerations, in a transparent and consistent process. They could provide a common metric for curative and preventive interventions to clearly define best health improvements within resource available, as recently advocated by Volp and colleagues [74]. They may also provide a road map to develop more participative decisionmaking processes by "better combining of many elements" proposed by Culyer [75].

Competing interests

The author(s) declare that they have no competing interests.

\section{Authors' contributions}

LAG, MMG, and MW designed the study, collected and analyzed the data and drafted the manuscript. RB, DR, JVT and PK contributed to the design and analyses and reviewed the manuscript. All authors read and approved the final manuscript.

\section{Acknowledgments}

This study was partially funded by a grant from the Canadian Institutes of Health Research (CIHR \# 228208).

\section{Author details}

${ }^{1}$ BioMedCom Consultants, Montreal, Quebec, Canada. ${ }^{2}$ Department of Primary and Community Care, Radboud University Nijmegen Medical Centre, Nijmegen, The Netherlands. ${ }^{3}$ University of Twente, Enschede, The Netherlands. ${ }^{4}$ York University, Toronto, ON, Canada. ${ }^{5}$ Department of Health Administration, Faculty of medicine, University of Montreal, Montreal, Canada.

Received: 20 January 2012 Accepted: 28 June 2012 Published: 18 July 2012 


\section{References}

1. Hsu M, Anen C, Quartz SR: The right and the good: distributive justice and neural encoding of equity and efficiency. Science 2008, 320:1092-1095.

2. World Health Organization: Guidance on ethics and equitable access to HIV treatment and care. http://www.who.int/ethics/Guidance\%20on\%20Ethics\% 20and\%20HIV.pdf.

3. Daniels N: Justice, health, and healthcare. Am J Bioeth 2001, 1:2-16

4. Gruskin S, Daniels N: Process is the point: justice and human rights: priority setting and fair deliberative process. Am J Public Health 2008, 98:1573-1577.

5. Persad G, Wertheimer A, Emanuel EJ: Principles for allocation of scarce medical interventions. Lancet 2009, 373:423-431.

6. Daniels N, Sabin J: Limits to health care: fair procedures, democratic deliberation, and the legitimacy problem for insurers. Philos Public Aff 1997, 26:303-350.

7. Daniels N: Decisions about access to health care and accountability for reasonableness. J Urban Health 1999, 76:176-191.

8. Asante $A D, Z$ wi $A B$ : Factors influencing resource allocation decisions and equity in the health system of Ghana. Public Health 2009, 123:371-377.

9. Andreae MC, Lamarand KE, Abraham L, Freed GL: Basis for immunization recommendations among countries of the World Health Organization European region. Hum Vaccin 2009, 5:754-760.

10. Goetghebeur MM, Wagner M, Khoury H, Rindress D, Gregoire JP, Deal C: Combining multicriteria decision analysis, ethics and health technology assessment: applying the EVIDEM decisionmaking framework to growth hormone for Turner syndrome patients. Cost Eff Resour Alloc 2010, 8:4.

11. Baltussen R, Niessen L: Priority setting of health interventions: the need for multi-criteria decision analysis. Cost Eff Resour Alloc 2006, 4:14

12. Baltussen $R$, ten Asbroek $A H$, Koolman $X$, Shrestha N, Bhattarai P, Niessen LW: Priority setting using multiple criteria: should a lung health programme be implemented in Nepal? Health Policy Plan 2007, 22:178-185.

13. Youngkong S, Kapiriri L, Baltussen R: Setting priorities for health interventions in developing countries: a review of empirical studies. Trop Med Int Health 2009, 14:930-939.

14. Lasry A, Carter MW, Zaric GS: Allocating funds for HIV/AIDS: a descriptive study of KwaDukuza, South Africa. Health Policy Plan 2010, 26:33-42.

15. Bowen S, Zwi AB: Pathways to "evidence-informed" policy and practice: a framework for action. PLoS Med 2005, 2:e166

16. Browman GP, Manns B, Hagen N, Chambers CR, Simon A, Sinclair S: 6-STEPPPs: a modular tool to facilitate clinician participation in fair decisions for funding new cancer drugs. J Oncol Pract 2008, 4:2-7.

17. Ghaffar A: Setting research priorities by applying the combined approach matrix. Indian J Med Res 2009, 129:368-375.

18. Goetghebeur M, Wagner M, Khoury H, Levitt RJ, Erickson LJ, Rindress D: Evidence and Value: impact on DEcisionMaking - the EVIDEM framework and potential applications. BMC Health Serv Res 2008, 8:270.

19. Golan OG, Hansen P: A new decision-support framework for prioritization of new health technologies. University of Otago: The 'value for money' chart; 2010.

20. Hailey D: A preliminary survey on the influence of rapid health technology assessments. Int I Technol Assess Health Care 2009, 25:415-418.

21. Honore PA, Fos PJ, Smith T, Riley M, Kramarz K: Decision science: a scientific approach to enhance public health budgeting. J Public Health Manag Pract 2010, 16:98-103.

22. Johnson AP, Sikich NJ, Evans G, Evans W, Giacomini M, Glendining M, et al: Health technology assessment: a comprehensive framework for evidence-based recommendations in Ontario. Int J Technol Assess Health Care 2009, 25:141-150

23. Kirby J, Somers E, Simpson C, McPhee J: The public funding of expensive cancer therapies: synthesizing the "3Es"-evidence, economics, and ethics. Organ Ethic 2008, 4:97-108.

24. Meagher T: MUHC clinical activity priority setting A4R and beyond. Boston: Presented at the 8th Biennial Conference of the International Society on Priorities in Health Care; 2010
25. Menon D, Stafinski T, McCabe C: To fund or not to fund: A generalized decision-making model for health care resource allocation. Boston: Presented at the 8th Biennial Conference of the International Society on Priorities in Health Care; 2010.

26. Tannahill A: Beyond evidence-to ethics: a decision-making framework for health promotion, public health and health improvement. Health Promot Int 2008, 23:380-390.

27. The University of York: Providing reliable evidence to support decision-making.: The NHS Economic Evaluation Database (NHS EED); http://www.york.ac.uk/ inst/crd/EM/em61.pdf.

28. Wilson EC, Rees J, Fordham RJ: Developing a prioritisation framework in an English primary care trust. Cost Eff Resour Alloc 2006, 4:3.

29. EVIDEM Collaboration: EVIDEM Collaboration. http://www.evidem.org.

30. Baltussen R, Stolk E, Chisholm D, Aikins M: Towards a multi-criteria approach for priority setting: an application to Ghana. Health Econ 2006, 15:689-696.

31. Dionne F, Mitton C, Smith N, Donaldson C: Evaluation of the impact of program budgeting and marginal analysis in Vancouver Island Health Authority. J Health Serv Res Policy 2009, 14:234-242.

32. Dolan JG: Multi-criteria clinical decision support. A primer on the use of multiple-criteria decision-making methods to promote evidence-based, patient-centered healthcare. Patient 2010, 3:229-248.

33. Duthie T, Trueman P, Chancellor J, Diez L: Research into the use of health economics in decision making in the United Kingdom--Phase II. Is health economics 'for good or evil'? Health Policy 1999, 46:143-157.

34. Gibson J, Mitton C, Martin D, Donaldson C, Singer P: Ethics and economics: does programme budgeting and marginal analysis contribute to fair priority setting? J Health Serv Res Policy 2006, 11:32-37.

35. Hofmann B: Toward a procedure for integrating moral issues in health technology assessment. Int J Technol Assess Health Care 2005, 21:312-318.

36. Irving MJ, Tong A, Rychetnik L, Walker RG, Frommer MS, Craig JC: Nephrologists' perspectives on the effect of guidelines on clinical practice: a semistructured interview study. Am J Kidney Dis 2010, 55:241-249.

37. Jehu-Appiah C, Baltussen R, Acquah C, Aikins M, D'Almeida SA, Bosu WK, e al: Balancing equity and efficiency in health priorities in Ghana: the use of multicriteria decision analysis. Value Health 2008, 11:1081-1087.

38. Kapiriri L, Norheim OF, Martin DK: Fairness and accountability for reasonableness. Do the views of priority setting decision makers differ across health systems and levels of decision making? Soc Sci Med 2009, 68:766-773.

39. Koopmanschap MA, Stolk EA, Koolman X: Dear policy maker: have you made up your mind? A discrete choice experiment among policy makers and other health professionals. Int J Technol Assess Health Care 2010, 26:198-204.

40. Lehoux $P$, Williams-Jones B: Mapping the integration of social and ethica issues in health technology assessment. Int J Technol Assess Health Care 2007, 23:9-16

41. Lopert R: Evidence-based decision-making within Australia's pharmaceutical benefits scheme. Issue Brief (Commonw Fund) 2009, 60:1-13.

42. Martin DK, Pater JL, Singer PA: Priority-setting decisions for new cancer drugs: a qualitative case study. Lancet 2001, 358:1676-1681.

43. Mitton C, Mackenzie J, Cranston L, Teng F: Priority setting in the Provincial Health Services Authority: case study for the 2005/06 planning cycle. Healthc Policy 2006, 2:91-106.

44. Mullen PM: Quantifying priorities in healthcare: transparency or illusion? Health Serv Manage Res 2004, 17:47-58.

45. Noorani HZ, Husereau DR, Boudreau R, Skidmore B: Priority setting for health technology assessments: a systematic review of current practical approaches. Int J Technol Assess Health Care 2007, 23:310-315.

46. Saarni SI, Hofmann B, Lampe K, Luhmann D, Makela M, Velasco-Garrido M, et al: Ethical analysis to improve decision-making on health technologies. Bull World Health Organ 2008, 86:617-623.

47. Vuorenkoski $L$, Toiviainen $H$, Hemminki E: Decision-making in priority setting for medicines-a review of empirical studies. Health Policy 2008, 86:1-9.

48. Wilson E, Sussex J, Macleod C, Fordham R: Prioritizing health technologies in a primary care trust. J Health Serv Res Policy 2007, 12:80-85.

49. Wirtz V, Cribb A, Barber N: Reimbursement decisions in health policyextending our understanding of the elements of decision-making. Health Policy 2005, 73:330-338. 
50. Gibson JL, Martin DK, Singer PA: Evidence, economics and ethics: resource allocation in health services organizations. Healthc Q 2005, 8:50-9. 4.

51. Bowen S, Erickson T, Martens PJ, Crockett S: More than "Using Research": the real challenges in promoting evidence-informed decision-making. Health Policy 2009, 4:87-102.

52. Wilson KA, Carwardine J, Possingham HP: Setting conservation priorities. Ann N Y Acad Sci 2009, 1162:237-264.

53. Walton NA, Martin DK, Peter EH, Pringle DM, Singer PA: Priority setting and cardiac surgery: a qualitative case study. Health Policy 2007, 80:444-458.

54. Schlander M: The use of cost-effectiveness by the National Institute for Health and Clinical Excellence (NICE): no(t yet an) exemplar of a deliberative process. J Med Ethics 2008, 34:534-539.

55. van Velden ME, Severens $J$, Novak A: Economic evaluations of healthcare programmes and decision making: the influence of economic evaluations on different healthcare decision-making levels. PharmacoEconomics 2005, 23:1075-1082.

56. Williams I, Mclver S, Moore D, Bryan S: The use of economic evaluations in NHS decision-making: a review and empirical investigation. Health Technol Assess 2008, 12. iii, ix-iii,175.

57. World Health Organization Regional Committee for South-East Asia: Equity in access to public health. New Delhi, India: Working paper from the 53rd session of the WHO Regional Committee for South-East Asia; 2000. 4-7 September 2000

58. Braveman P, Gruskin S: Defining equity in health. J Epidemio/ Community Health 2003, 57:254-258.

59. Giacomini M: How good is good enough? Standards in policy decisions to cover new health technologies. Healthc Policy 2007, 3:91-101.

60. Nord E, Daniels N, Kamlet M: QALYs: some challenges. Value Health 2009, 12(Suppl 1):S10-S15

61. Goetghebeur MM, Wagner M, Khoury H, Levitt RJ, Erickson LJ, Rindress D: Bridging health technology assessment (HTA) and efficient health care decision making with multicriteria decision analysis (MCDA): applying the EVIDEM framework to medicines appraisal. Med Decis Making 2011

62. Culyer AJ, Bombard Y: An equity framework for health technology assessments. Med Decis Making 2012, 32:428-441.

63. Burls A, Caron L, de Cleret LG, Dondorp W, Harstall C, Pathak-Sen E, et al: Tackling ethical issues in health technology assessment: a proposed framework. Int J Technol Assess Health Care 2011, 27:230-237.

64. Hawkes N: Health technology assessment. NICE goes global. BMJ 2009 338:b103.

65. Biomedcom Consultants Inc: Interface database on coverage decisionmaking processes in jurisdictions around the globe. 2011. http://www.biomedcom. org/en/bmc-databases.php.

66. Diaby $V$, Laurier $C$, Lachaine J: A proposed framework for formulary listing in low-income countries. Pharm Med 2011, 25:71-82.

67. Eichler HG, Pignatti F, Flamion B, Leufkens $H$, Breckenridge A: Balancing early market access to new drugs with the need for benefit/risk data: a mounting dilemma. Nat Rev Drug Discov 2008, 7:818-826.

68. Luce BR, Drummond M, Jonsson B, Neumann PJ, Schwartz JS, Siebert U, et al: EBM, HTA, and CER: clearing the confusion. Milbank Q 2010, 88:256-276.

69. Chalkidou K, Tunis S, Lopert R, Rochaix L, Sawicki PT, Nasser M, et al: Comparative effectiveness research and evidence-based health policy: experience from four countries. Milbank Q 2009, 87:339-367.

70. Erickson LJ, De WP, Farand L: An analytical framework for immunization programs in Canada. Vaccine 2005, 23:2470-2476.

71. Drummond M, Evans B, LeLorier J, Karakiewicz P, Martin D, Tugwell P, et al: Evidence and values: requirements for public reimbursement of drugs for rare diseases-a case study in oncology. Can J Clin Pharmacol 2009, 16:e273-e281.

72. Lomas J, Culyer T, McCutcheon C, McAuley L, Law S: Conceptualizing and combining evidence for health system guidance. http://www.chsrf.ca/ kte_docs/Conceptualizing\%20and\%20combining\%20evidence.pdf.

73. Baltussen R, Youngkong S, Paolucci F, Niessen L: Multi-criteria decision analysis to prioritize health interventions: capitalizing on first experiences. Health Policy 2010, 96:262-264.
74. Volpp KG, Loewenstein G, Asch DA: Assessing value in health care programs. JAMA 2012, 307:2153-2154.

75. Culyer AJ: Hic sunt dracones: the future of health technology assessment-one economist's perspective. Med Decis Making 2012, 32:E25-E32.

doi:10.1186/1478-7547-10-9

Cite this article as: Guindo et al:: From efficacy to equity: Literature review of decision criteria for resource allocation and healthcare decisionmaking. Cost Effectiveness and Resource Allocation 2012 10:9.

\section{Submit your next manuscript to BioMed Central and take full advantage of:}

- Convenient online submission

- Thorough peer review

- No space constraints or color figure charges

- Immediate publication on acceptance

- Inclusion in PubMed, CAS, Scopus and Google Scholar

- Research which is freely available for redistribution 